\title{
Environmental Ethics Perspective of Sustainable developing and utilizing of urban lakes ---Taking the Comprehensive Measures of Wuhan Urban Lakes as the Example
}

\author{
Yong-zhi Chen, Xue-kuan Yu, Zuo-qin Qian \\ School of energy and power engineering, Wuhan University of Technology, Wuhan, 430063, Hubei
}

\begin{abstract}
Urban lakes are important water body for a city. It plays an important role in the climate regulation and ecological environment construction of the city, and it is a true reflection of ecology culture for the city. However, with the rapid development of socialism modernize build of China, how to keep the balance of the urban construction, the development of urban lake and the urban ecosystem becomes an outstanding issue. So, taking Wuhan as the example, this paper discusses the environmental ethic problem and its causes which aroused by developing and utilizing of urban lakes. Based on this, the harmonious development strategies of the human -lakes- the city are raised.
\end{abstract}

Keywords — The city; Lakes; Sustainable development; Comprehensive treatment; environmental ethic

\section{环境伦理视野下的城市湖泊可持续开发和利用 ----以武汉市湖泊综合治理为例}

陈永志 于学宽 钱作勤

武汉理工大学能源与动力工程学院, 武汉, 湖北, 中国

摘 要 城市湖泊是城市的重要水体形态, 在城市的气候调节和生态环境建设中起着重要作用, 是城市生态文化的真实写照。然而, 随着我国社会主义城镇化建设的不断推进, 如何平衡城市建设、湖泊开发与城市生态环境的关系, 成为一个较为突出的问题摆在我们 面前。因此, 本文以“百湖之市”武汉为例, 阐述了城市湖泊开发利用引发的环境伦理问题及其成因, 在此基础上提出了实现人一湖泊 一城市系统整体和谐发展的对策。

关键词 城市; 湖泊; 可持续开发; 综合治理; 环境伦理

良好生态环境是人和社会持续发展的根本基础, 党的 十八大报告提出: “大力推进生态文明建设, 加大自然生态 系统和环境保护力度, 扩大森林、湖泊、湿地面积, 保护 生物多样性”[1]。把生态文明写入党代会报告, 这是党执政 兴国理念的新发展。湖泊是地球上主要淡水之源, 地球表 面上可利用的淡水资源 $90 \%$ 以上都由湖泊蓄积。湖泊是人 类赖以生存和发展的基础性自然资源, 它与人类的生产、 生活息息相关, 具有十分重要的社会意义和生态功能[2]。
城市湖泊是指位于我国一些大中城市市区或近郊的小 型湖泊, 是城市的重要水体形态, 具有观光游览、调节气 候等作用; 城市湖泊还兼有水上运动、水产养殖、农业灌 溉、工业用水等功能; 此外, 一些湖泊为各种生物提供了 重要的栖息地, 它们是生物多样性湿地生态系统的重要组 成部分[2], 因而, 城市湖泊可开发利用在城市规划建设中 占有十分重要的地位。然而, 随着城市经济的快速发展和 人们对环境要求的提高, 新的旅游景点、房产小区和高尔

基金项目：2011 年湖北省高等学校省级教学研究项目, 鄂教高函〔2011〕32 号 
夫球场在开发时也越来越多地融入人工湖的设计元素。如 何平衡城市建设、旅游开发与城市生态环境的关系, 如何 正确处理好城市湖泊开发与保护中的矛盾成为较为突出的 问题摆在我们面前[3]。

\section{1. 城市湖泊开发利用引发的环境伦理问题及其成因}

\section{1 湖泊数量减少、面积锐减}

随着城镇化建设速度的快速推进和经济建设的迅猛发 展, 而人们缺乏资源和环境保护意识[4], 长期围湖造田和 城市建设的掠夺性开发, 致使湖泊数量不断减少, 而面积 也骤减, 城市湖泊开发面临从曾经的“优于水”到如今“忧于 水”的局面。最近发布的《长江保护与发展报告 2011》显示, 近 30 年来长江流域消失面积在 1 平方公里以上的湖泊 96 个。来自我国第二次湖泊调查的最新数据显示, 近 50 年来, 我国消失的面积大于 1 平方公里的湖泊多达 243 个。同样, 曾经的武汉市，湖泊星罗棋布，遍布三镇，被人们誉为“百 湖之市”, 湖泊成为广大市民的骄傲。但是, 据武汉市水务 局最新的调查数据，从 1986 年到 2006 年，武汉市城市建 设总面积虽然增加了 200 多平方公里, 与此同时, 武汉市 湖泊的面积也减少了 200 多平方公里, 大约 100 个湖泊人 间“蒸发”, 杨汊湖、范湖等耳熟能详的名字现在只是带“湖”
字的符号。目前武汉市中心城区仅存湖泊 38 个, 并且它们 同样面临着被继续侵占的危险。面对严峻的湖泊保护形势, 武汉市市委书记阮成发多次在重要会议上高声疾呼: 我们 “要像爱护自己的眼睛一样爱护湖泊”! 并且“要以对历史负 责的态度，来治理湖泊，保护湖泊”! 我国湖泊与水资源环 境研究领域权威专家金伯欣教授呼吁: “政府当需铁腕治 湖，市民也应主动保护”。

武汉市湖泊数量不断减少、面积骤减, 不仅有特殊历 史背景下围湖造地、围湖养鱼的“历史之歾”，同时还有因 城市建设发展而填湖造房的“发展之歾”, 更重要的是屡禁 不止违法填湖的“现实之攻”。武汉市曾经“优于水”，如今却 “忧于水”, 正如武汉市民呼呼的: 我们要“沙湖”不要“杀湖”。

\section{2 湖泊水资源污染严重}

由于城市污水处理率过低, 绝大部分的污水未经任何 处理直接排入江河湖泊, 致使纳污水体污染严重。如汉阳 月湖水域面积仅为 $0.66 \mathrm{~km} 2$, 周边排污口多达 22 个。在武 汉市的建设发展过程中, 绝大多数城内湖泊均受到严重污 染, 呈现中度富营养状态，一些湖泊已达到重度富营养状 态[5]，见表 1 。

表 1 武汉市城区主要湖泊分级（2010 年）

\begin{tabular}{|l|l|l|l|l|l|}
\hline 分级 & 贫营养状态 (I) & 中营养状态 (II) & 轻度富营养状态 (III) & 中度富营养状态 (IV) & 重度富营养状态 (V) \\
\hline 汉口 & & & & 竹叶海、张毕海、西湖、 & $\begin{array}{l}\text { 小南湖、菱角湖、后襄湖、塔 } \\
\text { 子湖、机器荡子、北湖 }\end{array}$ \\
\hline 汉阳 & & & & & $\begin{array}{l}\text { 月湖、北太子湖、南太子湖、 } \\
\text { 龙阳湖、墨水湖、花湖 }\end{array}$ \\
\hline 武昌 & & & 严西湖 & $\begin{array}{l}\text { 东湖、紫阳湖、四美塘、 } \\
\text { 水果湖、杨春湖 }\end{array}$ & $\begin{array}{l}\text { 晒湖、南湖、内沙湖、外沙湖、 } \\
\text { 野芷湖 }\end{array}$ \\
\hline
\end{tabular}

以东湖为例, 由于多年人为干扰, 东湖已经成为典型 的过富营养化的城市景观湖泊。20世纪 50 年代为轻度富营 养型湖泊初期, 浮游植物以甲藻和硅藻为主; 60 年代进入 中度富营养型阶段, 浮游植物以蓝藻、绿藻为主; 70 年代 进入重度富营养型阶段[6]。据统计, 2010 年武汉市的主要 湖泊中, 大都处于IV和V级, 据湖北省环保厅、省环境监测 中心站 2012 年发布的 3 月份环境质量月报, 武汉东湖水质 有所好转: 水果湖水质持平, 仍为 $\mathrm{IV}$ 类。墨水湖水质仍为 劣 V 类。 2013 年北太子湖、机器荡子、菱角湖、鲁湖、内 沙湖、四美塘和小南湖等 7 个湖泊水质变差。

\section{3 湖泊生物的多样性遭到破坏}

湖泊的变化给生物多样性也带来了重大影响, 使得湖 泊的生态环境遭到严重破坏，物种逐年减少。最具代表性 的是, 长江流域多数湖泊土著鱼类受外来物种入侵、江湖 阻隔和过捕滥捞等因素影响而濒危。而武汉市的东湖的主 要水生植物在 1963 年还有 29 科 83 种, 到 1994 年, 调查 结果显示水生植物只有 29 科 62 种, 到 2001 年只有 20 科 33 种, 而到了 2007 年降至 11 科 18 种, 水生生物种类逐年 呈明显减少趋势，而耐污物种成为优势种。浮游植物 20 世 纪 50 年代有 111 种, 到 2007 年仅有 39 种, 种类减少明显, 
且不耐污种几乎绝迹。浮游植物平均每毫升数量 20 世纪 50 年代为几百个, 60 年代约近千个, 90 年代为 68000 个, 2007 年调查数据为 47000 个, 呈显著增加趋势。鱼类 20 世纪 70 年代有 19 科 67 种, 1994 年仅有 10 科 39 种, 减少种类以 洄游性和长江鱼类居多。鱼类以人工放养品种为主, 鲢、 鳙占渔获总量的比例由 1973 年的 $76 \%$ 上升至 1994 年的 $97 \%$, 天然鱼类种群普遍较小。鸟类与 20 世纪 80 年代初 相比, 鸟类种类约减少了一半, 其中候鸟种类减少较多, 许多有记载的珍稀候鸟（如小天鹅、白琵鹭、普通秋沙鸭、 灰鹤、猛禽和燕隼等) 已无分布。底栖动物 20 世纪 60 年 代初有 128 种, 1995 年有 67 种, 2003 年有 11 种, 2007 年 仅有 18 种, 种类总体呈逐年递减趋势。2007 年调查结果显 示未发现毛翅目幼虫等敏感种, 软体动物减少明显, 耐污 种如霍甫水丝蚓和摇蚊已成为优势种[7]。

\section{2. 人一湖泊一城市系统的整体和谐发展对策}

2.1 改革管理体制、加强制度与法规建设

城市湖泊综合治理是一项集社会效益、经济效益、环 境效益和政治效益于一体的综合性系统工程, 工程量大, 涉及面广, 情况复杂、工程建设要统一领导, 又要分工负 责, 层层把关, 高度重视[6]。党的十八大报告指出:“保护 生态环境必须依靠制度。要把资源消耗、环境损害、生态 效益纳入经济社会发展评价体系, 建立体现生态文明要求 的目标体系、考核办法、奖惩机制”[1]。必须加强城市湖泊 的制度和法规建设, 改革湖泊开发和利用的管理体系, 使 城市湖泊综合治理工作做到有法可依、有法可行, 从源头 上控制湖泊的污染 [8]。作为一个湖泊资源特色较为突出的 城市, 武汉市直到 2002 年 3 月才正式颁布具有法律效应的 《武汉市湖泊保护条例》, 在此之前虽然武汉出台过相关的 湖泊保护法令, 但是填湖和湖泊污染问题依然屡禁不止, 这一方面是来自于经济利益驱动, 另一方面则是由法制和 管理体制不健全所造成的。从 1989 到 1999 这十年间, 武 汉主城区有 8 个湖泊完全被填占, $85 \%$ 以上的湖泊出现了不 同程度的富营养化和污染, 同时湖泊利用各自为政, 严重 影响湖泊可持续开发与利用[5]。2013 年武汉市 6 位市领导、 32 家责任单位负责人分别围绕“十个突出问题”做出限期整 改承诺, 接受社会各界监督。加强湖泊保护与污染治理再 次成为武汉市承诺整改的“十个突出问题”之一。
2.2 加大高科技含量工程的投入, 重点实施湖泊生态修复工 程

近年来, 武汉市政府已认识到湖泊在城市发展中的名 片作用, 在湖泊保护方面也做了诸多努力, 实施“一湖一 景”、“清水入湖”、“大东湖水网”等一系列的城市湖泊治理 重大工程。目前, 武汉市投资近 2.5 亿元, 实施保护治理城 区湖泊的 6 大工程, 分别为“湖泊岸线固定、垃圾渣土清挖、 违法建筑拆除、环湖路畅通、排污口截流及岸坡整修工程”, 重点是要保障武汉市中心城区 40 个湖泊的形态稳定, 杜绝 䖯食填湖行为, 做到还湖于民。另外, 武汉市正投资 150 亿元实施“大东湖”生态水网工程, 如图 1 所示, 是以东湖 为中心, 以东沙湖水系、北湖水系为主要组成部分的江、 湖、港、渠组成的庞大水网, 它要将水域面积达 62.6 平方 公里的 6 个主要湖泊连通, 远期还将拓展到与汤逊湖水系 中的南湖、汤逊湖以及与梁子湖水系连通, 实现江湖相济, 构建生态水网湿地群。通过辅以水体生态保护与修复措施, 使整个“大东湖”水系的水生态环境得到改善, 重建多样性 的动植物生长、栖息、繁殖场所, 再现自然生态的天堂。 同时, 武汉市正在力图建成中国规模最大的城市中湿地公 园, 工程投资达到了 15872 亿元。

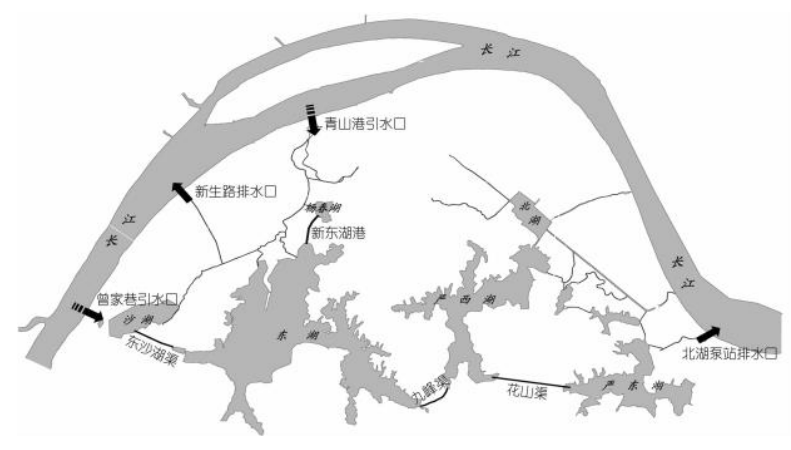

图 1 大东湖水系与水网连通工程布置示意

2009 年 11 月, 武汉举行了世界湖泊大会, 发出了“让 湖泊休养生息”的《武汉宣言》。武汉市将湖泊水环境作为 修复对象, 逐步探索出一套适用于防止城市湖泊严重富营 养化的综合治理技术和管理体系, 提高工程的科技含量, 重点实施湖泊生态修复工程, 具有十分重要的现实意义和 推广应用价值。

2.3 发展城市湖泊经济, 发掘相关产业新的增长点

统筹城市湖泊经济开发与城市环境保护, 积极寻找城 市湖泊相关产业新的增长点[9]。调查结果显示, 自 1990 年 
以来, 饮用水供给和污水处理市场在全球需有量增长居首。 目前, 我国 $90 \%$ 以上城市湖泊都受到了不同程度的污染, 约有 7 亿人在饮用大肠杆菌含量超标的水, 而 1.7 亿人饮用 被有机物污染的水, 并且 3 亿城市居民正面临水污染这一 世界性问题。据对全国 50 个代表性湖泊的综合评价， $75 \%$ 以上的湖泊水质受到不同程度污染, 超过 $\mathrm{V}$ 类水质的湖泊 15 个, 占 $30 \%$; 对全国 50 个代表性水库的调查表明, III 类水质以上的水库数量为 17 个, 占 $34 \%$ 。武汉地区科研院 所和大专院校云集, 污水处理科研实力居国内前列。结合 国家重大科研项目和重大研究计划的实施, 并以由此形成 的城市湖泊综合治理和可持续开发与利用技术以及相关管 理体系为基础, 突出重点, 积极引导一批科技型的水体环 境修复专业队伍, 形成产学研紧密结合的模式, 建立具有 一定特色的水体生态修复和湖泊富营养化防治技术为重点 环保产业基地, 进而辐射并向国内其他条件适宜的地区进 行推广, 发展地方水经济, 使之形成地方经济发展新的产 业增长点[6]。

寻求城市湖泊生态旅游开发项目, 形成城市旅游新的 增长点。2009 年, 武汉市投资近 40 亿在东湖岸边兴建欢乐 谷大型游乐项目。在建设过程中开发商华侨城承诺“不改变 一寸东湖湖岸线、不占用一寸东湖湖面、全力提升和改善 区域生态环境”。该项目已于 2011 年试运营, 据统计, 2012 年十一黄金周武汉市全市纳入旅游统计的景区纳客 72.33 万人次, 同比增长 $25.89 \%$, 收入 2567.5 万元, 同比增长 $66.27 \%$, 其中在所有景区中, 华侨城欢乐谷和东湖景区成 大最大热门景点。

\section{4 推进城市湖泊文化建设, 提高市民生态文明意识}

充分利用网络、报刊、电视等相关媒体, 加大城市湖 泊综合治理的宣传力度, 推进城市湖泊文化建设, 提高市 民生态文明意识, 使广大市民充分认识到城市湖泊的可持 续开发与利用是关系到国计民生和城市生存与发展、城市 认同感提升的百年大计, 是关系到市民切身利益的德政工 程, 使之增强治水的责任感和紧迫感。积极创造条件, 开 展生态示范区文化活动创建工作, 使全市大兴爱湖爱市爱 环保之风, 做到“优于水且兴于水”[6]。
武汉市市长唐良智在湖泊治理大会上多次痛陈当前湖泊开 发和利用最突出的四个问题: “垃圾围湖现象十分严重; 环 湖无序开发屡禁不止; 湖泊水质污染仍未得到根本遏制; 湖泊长效管理机制尚未真正建立”。为此, 成立了以市长为 组长的湖泊综合治理工作领导小组, 要“铁腕治湖”, 还湖 于民, 真正做到“让湖泊走近市民, 让市民亲近湖泊”, 形 成人-湖泊-城市系统的整体和谐发展。

\section{参考文献(References)}

[1] HU Jintao. Unswervingly along the path of socialism with Chinese characteristics to strive to build a well-off society in an all-round way. The People's Daily, 2012.11.18.01 version

[2] CHENG Ying, PEI Zongping. Lake pollution characteristics and repair technology. Modern agricultural science and technology, 2008 (01)

[3] WEI Yong. Exhibition development and management of environmental ethics review. Nanjing forestry university degree theory, 2012

[4] YU Mouchang. Ecological ethics, from theory to practice. Beijing: capital normal university press, 1999

[5] LIU Yaobin WANG Qifang, CHEN Hongmei. The development of the lakes in wuhan city, protection and development planning idea. Journal of economic geography, 2004 (24)

[6] Wang evergreen, yonghong wu and jian-tong liu. Wuhan city lake water environment situation and the comprehensive improvement of way. Journal of resources and environment in Yangtze river basin, 2004 (13)

[7] LEI Mingjun, JIANG Guzheng (Changjiang Water Resources Protection Institute, Changiiang Water Resources Commission, Wuhan 430051, China)

[8] WANG Ziyan. Environmental ethics theory and practice. Beijing: people's publishing house, 2007

[9] NI Ruihua. Ethical spirit of sustainable development. Beijing: China social sciences press, 2005. 